\title{
Caries Prevention by Arginine Metabolism in Oral Biofilms: Translating Science into Clinical Success
}

\author{
Marcelle M. Nascimento • Robert A. Burne
}

Published online: 12 January 2014

(C) Springer International Publishing AG 2014

\begin{abstract}
Knowledge acquired from microbiological studies of oral arginine metabolism over the past 40 years has recently found its way to clinical application in dentistry. Novel arginine formulations incorporated into dentifrices have proven to be effective as an approach to prevent dental caries. In oral biofilms, arginine metabolism via the arginine deiminase system (ADS) produces ammonia, which inhibits tooth demineralization by neutralizing glycolytic acids and by suppressing the emergence of a cariogenic microflora. Evidence from translational science studies suggests that arginine metabolism in oral biofilms decreases the risk for caries development. These studies have expanded the focus of caries research beyond cariogenic bacteria to health-related, ADS-positive bacteria. The focus of this article is on the contribution of arginine metabolism to $\mathrm{pH}$ homeostasis in oral biofilms and its impact on the etiology of dental caries.
\end{abstract}

Keywords Arginine deiminase · Biofilm · Plaque .

Microflora $\cdot$ Caries $\cdot \mathrm{pH}$

\section{Introduction}

Oral bacteria that colonize the teeth form dental plaque, a multispecies microbial biofilm associated with the development

M. M. Nascimento $(\bowtie)$

Department of Restorative Dental Science, Division of Operative Dentistry, College of Dentistry, University of Florida,

1395 Center Drive, PO Box 100415,

Gainesville, FL 32610-0415, USA

e-mail:mnascimento@dental.ufl.edu

\section{R. A. Burne}

Department of Oral Biology, College of Dentistry, University of

Florida, 1395 Center Drive, PO Box 100424

Gainesville, FL 32610-0415, USA

e-mail: rburne@dental.ufl.edu of dental caries. A caries lesion occurs when acids produced by bacterial glycolysis of dietary carbohydrates cause demineralization of the tooth enamel. Continuous acidification of oral biofilms results in increases in the proportions of acidproducing and acid-tolerant organisms, a selective process that alters dental plaque $\mathrm{pH}$ homeostasis and shifts the demineralization-remineralization balance toward loss of tooth minerals. Thus, while caries is known as a multi-factorial disease, low $\mathrm{pH}$ is its primary determinant. Consequently, a major focus of caries research has been on identifying and characterizing acid-generating bacteria and the mechanisms of acid resistance of cariogenic bacteria. Yet, very few studies have directly examined the alkali-generating bacteria capable of effecting plaque neutralization, many of which appear critical to dental health. In particular, translational research efforts $[1,2$, $3 \bullet \bullet, 4]$ have suggested that alkali production in the form of ammonia inhibits tooth demineralization by neutralizing glycolytic acids and by creating an environment in oral biofilms more favorable to the persistence of an alkalinogenic microflora that is compatible with dental health. Therefore, alkali production in oral biofilms is closely intertwined with microbial ecology in health and diseases.

The metabolism of arginine by the arginine deiminase system (ADS) of oral bacteria results in ammonia production in plaque and contributes to the $\mathrm{pH}$ rise following the ingestion of carbohydrates and during fasting periods [5]. Arginine metabolism has also been shown to significantly increase plaque $\mathrm{pH}$ in vitro and in vivo, even in the presence of carbohydrates. The concentration of ammonia, usually in the form of ammonium ion $\left(\mathrm{NH}_{4}{ }^{+}\right)$, in plaque fluid can exceed $40 \mathrm{mM}$ [6], and a significant proportion of this ammonia can be derived from urea metabolism by ureases, as well as from some other ammonia-generating systems of oral bacteria such as amino acid deaminases $[7,8 \bullet]$. However, the ADS is considered to be a major contributor to plaque ammonia content and $\mathrm{pH}$ homeostasis [9]. Evidence from the early basic studies of Kleinberg 
and collaborators $[10,11]$ to more recent clinical studies correlating oral arginine metabolism and caries experience $[2,3 \cdot 0]$ suggested that providing arginine to oral biofilms could be an effective therapy for caries control. Indeed, the use of mints [12] and dentifrices [13-17] containing arginine was highly effective at inhibiting the initiation and progression of dental caries. This review will provide current information concerning the contribution of the ADS to $\mathrm{pH}$ homeostasis in oral biofilms and implications on the etiology of dental caries in the context of how arginine may positively influence the ecology of oral biofilms to foster dental health.

\section{ADS of Oral Bacteria}

The major sources of arginine for plaque bacteria are the diet and salivary peptides. Arginine in free form is secreted in saliva at concentrations averaging about $50 \mu \mathrm{M}$ [18], and free arginine is found in mature 48-h dental plaque at approximately $200 \mu \mathrm{M}$ [19]. Free arginine can also be introduced into the diet in particular foods. However, much of the arginine that enters the mouth in foods, or salivary and other host secretions, is in peptide or protein form. The arginine can then be released by the variety of proteases produced by the oral microbiota into a form that can be internalized and catabolized by abundant ADS-positive bacteria. The primary route for catabolism of arginine by plaque bacteria is via the threeenzyme ADS, which initially converts arginine into citrulline and ammonia using the enzyme arginine deiminase (AD). The citrulline thus generated is acted on by a catabolic ornithine transcarbamylase (cOTC) to produce ornithine and carbamyl phosphate. A catabolic carbamate kinase (cCK) cleaves carbamyl phosphate to ammonia and $\mathrm{CO}_{2}$, concomitantly donating the phosphate to ADP to produce ATP [7]. Ammonia production via the ADS results in cytoplasmic and environmental $\mathrm{pH}$ increases and benefits oral bacteria by: 1) protecting them against acid killing [7, 20];2) providing bioenergetic advantages that include increasing $\Delta \mathrm{pH}$ and synthesizing ATP [7, 21]; and 3) maintaining a relatively neutral environmental $\mathrm{pH}$ that is less favorable for the outgrowth of cariogenic microflora [7, 22]. Arginine metabolism via the ADS is hence deemed as beneficial to ADS-positive bacteria and has a potent influence on oral biofilm $\mathrm{pH}$, microbial ecology and on the initiation and progression of caries.

Generally, the ADS genes are arranged in operons consisting of $\operatorname{arcA}(\mathrm{AD}), \operatorname{arcB}(\mathrm{cOTC})$ and $\operatorname{arcC}$ (cCK) [23]. ADS operons can also harbor $\operatorname{arcD}$ (arginine/ornithine antiporter) and other genes encoding arginine amino peptidases and transcriptional regulators. Burne and Marquis [5] suggested that alkali production needs to be tightly regulated because excessive alkalinization could be lethal, or too vigorous catabolic activity by the ADS could deplete arginine supplies for protein synthesis. In fact, several regulatory mechanisms are well established for the ADS of oral bacteria. For example, arginine is required for induction of the ADS and the system is sensitive to carbon catabolite repression (CCR) in Streptococcus sanguinis, Streptococcus rattus and Streptococcus gordonii [5, 23-27]. The dependence on extracellular arginine for induction of ADS may be reduced during co-aggregation of arginolytic and non-arginolytic species [28]. The ADS also appears to require low $\mathrm{pH}$ and anaerobic conditions for optimal expression in some oral streptococci $[24,26,27]$. Specific and global transcriptional regulators, multiple two-component systems and other factors have been also shown to regulate ADS activity in response to arginine and environmental signals in $S$. gordonii through transcriptional and post-transcriptional mechanisms [5, 24, 26, 27]. Furthermore, ammonia production via the ADS appears to be inhibited by certain antimicrobials commonly used in oral care products, such as triclosan; although fluoride was considered a poor inhibitor of the ADS at levels normally found in the oral cavity [29].

The majority of recognized species of ADS-positive oral bacterial can be readily cultivated, and mostly consists of abundant oral streptococci: S. sanguinis, S. gordonii, S. rattus, Streptococcus parasanguinis, Streptococcus mitis, Streptococcus oralis, and Streptococcus cristatus. Some other oral bacteria are also known to express the ADS, including certain Lactobacillus species and a few spirochetes [7, 22, 30]. A human oral microbiome database (HOMD) meta-database search has shown potential "arginine deiminase" (AD) enzymes in over 130 taxa, so if the annotations of these genes are correct, the system may be present in many other oral bacteria. Although genome sequencing and other molecular techniques have revealed new levels of complexity in the cariogenic microflora and in the nature of individual bacterial species [31-35], limited attempts [36-38] have been made to identify and characterize the clinically relevant oral organisms capable of producing alkali, which by extension can potentially affect the cariogenicity of oral biofilms. While taxa/species-level identification of the arginolytic microbiota is valuable, it does not address the fact that there is significant heterogeneity within given species of oral bacteria [39], particularly in their abilities to moderate $\mathrm{pH}$ fall. Thus, the taxa/species-level identification studies need to be supported by phenotypic and functional studies to establish reliable correlations of specific organisms with health and disease.

\section{The Acid-Base Imbalance In Caries Development}

Markedly less is known about the production of alkali than is known about sugar metabolism in oral biofilms. The causal relationship between bacterial sugar metabolism and acid production by a mixed population of plaque bacteria was first described by Stephan [40], who also pointed out that the drop in plaque $\mathrm{pH}$ detected after sugar challenge is followed by a 
gradual rise in plaque $\mathrm{pH}$ that eventually reaches a plateau. Later, the plateau —or resting $\mathrm{pH}$ - of caries-active plaque was found to be more acidic than that of caries-free plaque [41], further supporting a correlation between acid production and dental caries. Subsequent studies showed that the rise in plaque $\mathrm{pH}$ is associated in part with ammonia production from arginine or urea by a subset of organisms present in saliva and plaque [42]. Marquis suggested [43] that the buffering capacity from ammonia production in oral biofilms moderates the speed of the $\mathrm{pH}$ drop and allows time for the alkali-producing bacteria to adjust their physiology for survival. Kleinberg foretold [44] that plaque $\mathrm{pH}$ would be determined by the acid-base metabolism of plaque organisms, which in turn could be affected by plaque thickness, the proportions of acid-producing and alkaliproducing organisms, and the relative availability of nitrogenous and carbohydrates substrates in plaque. In line with these early studies, data from a recent in vitro study showed that caries development may be influenced by the relative rates of acid and base formation in plaque, which critically depend on the presence of sucrose, the $\mathrm{pH}$ and buffer capacity of plaque, as well as the biofilm age [45].

Evidence accumulated from in vitro and clinical observations provides strong support for the idea that the ADS functions to reduce the cariogenicity of oral biofilms. A study from Singer and collaborators [46] was the first to indicate that the ADS is active in vivo in human dental plaque. Later, the levels of free arginine in saliva of caries-free individuals were found to be significantly higher than in saliva of those with caries [18]. This fact may explain in part why dental plaques of caries-free individuals who have fasted have elevated ammonia levels [47] and higher $\mathrm{pH}$ values compared to plaque from caries-active individuals [47-49]. Our research group has been conducting studies to differentiate caries-free and caries-active individuals on the basis of their ability to metabolize arginine via the ADS $[2,3 \cdot \bullet]$. A positive correlation between ADS activity in oral biofilms and absence of caries activity has been clinically demonstrated in adults [2], and more recently in children [3••]. Specifically, oral bacteria from plaque of caries-free individuals present higher ADS activity compared with those from caries-active individuals. In other words, the plaque bacteria of individuals who are caries-free appear to be able to utilize arginine to neutralize plaque acids more effectively than plaque bacteria of those who are experiencing caries.

When the arginolytic potential of bacteria collected from site-specific supragingival plaque was investigated in children [3••], it was observed that plaque bacteria colonizing tooth surfaces without carious lesions presented with a significantly greater capacity to metabolize arginine compared with plaque bacteria of carious lesions. Notwithstanding, an extremely high degree of variability in ADS activity among plaque samples was also observed, in some cases greater than 10,000-fold. Together, the findings from this study [3••] support two linked hypotheses: 1) alkali production via the ADS contributes to plaque $\mathrm{pH}$ homeostasis - an equilibrium of the bacterial acidbase metabolism - typical of dental health; and thus, 2) an individual or a tooth surface may be at higher risk for caries when there is a deficiency in alkali production via the ADS to counteract acid production from sugar metabolism.

One would expect that differences in the microbial composition of oral biofilms could be the most likely factor to affect the capacity of oral samples from different individuals and different tooth surfaces to metabolize arginine. Reduced ADS activity would appear to be due to low levels, or absence of, ADS-positive bacteria in oral biofilms. This would be predicted based on what is currently understood about caries and microbial ecology, simply because the proportions of acid tolerant and acidogenic species increase in cariogenic biofilms, which must occur at the expense of other species. However, the use of qPCR [2] did not reveal a statistically significant association between the proportions of two recognized arginolytic species, $S$. sanguinis and S. gordonii, and the caries status of adults. These results suggested that the diminution in ADS activity associated with caries experience may not be due only to lower proportions of known ADS-positive bacteria, and also raised the possibility that species other than those examined in that study may contribute to the overall oral ADS activity. Conversely, as the diversity of the oral microbiota associated with health and disease is beginning to be described by highthroughput methodologies [31-33, 35, 50-52], certain ADSpositive streptococci are underrepresented in cariogenic oral biofilms and consistently associated with dental health. For example, Gross and collaborators [51] used 16sRNA gene sequencing to investigate the bacterial community profiles associated with the progression of caries and with health. S. sanguinis were found at significantly higher levels in health as compared to the more advanced stages of caries, and $S$. gordonii and S. cristatus were found at higher levels in subjects with caries that did not progress as compared to those whose caries progressed [51]. Certainly, there is a critical need to more thoroughly characterize the organisms that contribute to arginolysis in the oral cavity.

A preliminary study [53] aimed to isolate and identify arginolytic bacterial strains from plaque samples. The majority of the ADS-positive bacterial species identified were strains of $S$. sanguinis and S. gordonii, but additional cultivable taxa such as species of Actinomyces, Bacillus, and Neisseria were also found to contribute to the total oral arginolysis. This study also examined the heterogeneity of the arginolytic strains in terms of differential sensitivity of the ADS to induction or repression by environmental factors. The results revealed a considerable spectrum of responses of the ADS to multiple environmental stimuli. The ADS of clinical strains was demonstrated to be regulated in response to those environmental factors that have the greatest impact on the composition and biochemical activities of supragingival biofilms - availability and source of carbohydrate, low $\mathrm{pH}$ 
and oxygen - and that are all well-recognized environmental factors that can influence the development of caries.

It is therefore possible that the basis for differences in arginolysis observed between caries-free and caries-active individuals can be associated with: 1) the carriage in oral biofilms of strains that have inherent differences in the regulation of the ADS by environmental factors; and/or 2) host and biofilm micro-environmental factors that affect ADS expression or activity in vivo. For example, the microenvironments in biofilms of caries-active individuals may not be conducive to high ADS expression or may contain inhibitory factors that decrease ADS expression or enzyme activity. Clearly, arginolytic clinical strains with constitutionally high ADSexpressing phenotypes and those in which ADS expression is insensitive to conditions known to cause caries-sugar availability and acidic environment-may have great potential in probiotic therapies to prevent and control dental caries. Future studies should assess whether there are associations of particular ADS-positive isolates having beneficial properties with health, or particular isolates having undesirable properties - aciduricity, poor arginolysis, poor antagonism against cariogenic organisms - with disease. Of note, the manipulation of ADS genes to produce strains of oral streptococci able to modulate the cariogenic potential of dental plaque has been previously proposed by Burne and collaborators [54]. They suggested that these strains could be developed either by engineering high ADS-expressing strains from organisms that normally possess the system, or through the introduction of the ADS genes into the caries pathogen Streptococcus mutans, which normally lacks the system.

\section{Arginine Versus Agmatine Deiminase}

Besides the ADS pathway, arginine can be enzymatically converted to agmatine. Agmatine can be produced from arginine by plaque bacteria that express the enzyme arginine decarboxylase (ADC), and agmatine can also be introduced into the oral cavity in a variety of foodstuffs [55]. Oral agmatine can be catabolized in a very similar manner as arginine by the ADS via the agmatine deiminase system (AgDS). Specifically, agmatine is acted on by agmatine deiminase to produce carbamylputrescine and one molecule of ammonia. Enzymes of the AgDS, which are similar to the cOTC and CK enzymes of the ADS, can then convert carbamylputrescine to putrescine, $\mathrm{CO}_{2}$, and ammonia while generating one molecule of ATP per molecule of agmatine catabolized [55, 56]. As with the ADS of other plaque streptococci, the AgDS of S. mutans contributes to $\Delta \mathrm{pH}$ by raising ammonia liberation in the cytoplasm and provides ATP, thereby contributing to acid tolerance [57]. However, the AgDS activity in oral biofilms is generally lower than that of ADS [57], and ammonia production from agmatine probably does not result in significant alkalinization of the environment, in contrast to arginine catabolism via the ADS $[55,56]$. Importantly, agmatine is inhibitory to the growth of S. mutans and AgDS activity is required for optimal growth of this organism in the presence of agmatine [55]. Thus, it has been proposed that the ability of the AgDS to detoxify and catabolize agmatine may augment the survival and cariogenic potential of certain bacteria, like $S$. mutans. Also of note, the $\mathrm{AgDS}$ is absent or only very poorly expressed in many of the plaque streptococci that have been most closely associated with dental health.

Even though the major route for arginine breakdown is the ADS [42, 58, 59], ADC and subsequently AgDS activities may be prominent in certain plaque samples. If this is the case, ADC and AgDS activities would have the effect of shifting catabolism of arginine away from a beneficial pathway, the ADS, to be catabolized by a pathway that may be more beneficial to caries pathogens, thus further shifting the balance from health to caries disease. It remains to be carefully tested whether oral biofilms of caries-free individuals have a greater capacity to metabolize arginine via ADS and lower capacity to metabolize agmatine via the AgDS compared to those from caries-active individuals.

A better understanding of the constitutional acid tolerance of certain arginolytic strains may help to explain the contribution of the ADS and AgDS to the ecology of oral biofilms. As previously mentioned, the ADS and AgDS are strongly protective against the effects of low $\mathrm{pH}[20,55]$. Work by van Houte, Beighton and others has revealed an association of non-mutans "low pH" bacteria, including streptococci, Actinomyces, Bifidobacterium/Scardovia and lactobacilli, with caries, and some of these species possess the ADS [31, 50, 60-65]. We propose that there is an inverse relationship between the levels of ADS and AgDS expression and the ability to tolerate and grow at low $\mathrm{pH}$ in the absence of arginine and agmatine, respectively. In fact, such associations are evident with groups of streptococci. For example, S. rattus is generally recognized as poorly cariogenic and not particularly acid tolerant, while it is the only member of the mutans group of streptococci that possesses the ADS. Therefore, there may be sub-groups of known "commensals" that are highly aciduric but insufficiently alkalinogenic to moderate oral biofilm acidification, and therefore are cariogenic. The capacity to differentiate these "commensals" from healthy organisms will immediately add clarity to the complex acid-base relationships in the oral microbiome.

\section{Novel Technologies Containing Arginine}

The effectiveness of the arginine metabolism on regulation of plaque $\mathrm{pH}$ seems to depend mostly on the availability of the arginine to act as an inducer and as a substrate for the ADS. A technology designed by Kleinberg [66] targeted to deliver arginine for ammonia production by plaque bacteria. This 
technology, when incorporated into mints or dentifrices, was demonstrated clinically to be successful in inhibiting caries initiation and progression in children at high risk for caries $[12,13]$. Thus far, only fluoride was considered clinically effective in preventing and reversing the caries process by favoring tooth remineralization during acidification from sugar metabolism. The mechanisms of action of arginine appear to complement that of fluoride by directly influencing $\mathrm{pH}$ while impacting the composition of oral biofilms.

A clinical study tested the hypothesis that increased availability of arginine in the oral environment through an exogenous source enhances the ADS activity levels in dental plaque and favorably influences the composition of the oral microbiome [67]. In this study, the use of a fluoride-free dentifrice containing arginine significantly increased ADS activity in plaque of caries-active individuals. The plaque microbial profiles of caries-active individuals treated with the arginine toothpaste also showed evidence of a shift in composition to that more similar to a health-associated community, i.e. more similar to that of caries-free individuals, as demonstrated by analyses using the Human Oral Microbe Identification Microarray (HOMIM). While these studies are preliminary and need to be confirmed with larger sample sizes, they point to the idea that an anti-caries effect may be expected from arginine-based formulations due in part to its ability to enhance ADS activity levels. If that is the case, then the beneficial effects could be realized from enhancement of arginine metabolism from salivary sources during fasting periods, which could favor tooth remineralization. Further, the higher resting plaque $\mathrm{pH}$ would translate to less extreme acidification of plaque when challenged with carbohydrates. And finally, continued enhancement of arginine metabolism should eventually lead to changes in, or stabilization of, the composition of the oral microbiome that would be beneficial to the host and selective against caries pathogens.

A series of clinical studies have recently confirmed the hypothesis that supplementation of arginine to plaque bacteria can be effective against caries [14-17]. In these studies, an optimized formulation containing arginine and fluoride and incorporated into a new dentifrice was proven to be significantly more effective in controlling caries in children than a dentifrice containing fluoride alone [14-17]. While these findings may have substantial public health benefits, the research community is now challenged by the fact that much remains to be investigated with respect to the effects of these novel argininebased oral care technologies on the composition, gene expression profiles and biochemical activities of the oral microbiota.

\section{Conclusion}

Arginine metabolism via the ADS contributes to $\mathrm{pH}$ homeostasis in oral biofilms and reduces the risk for development of carious lesions. Consequently, protection against dental caries may be achieved by increasing the alkali-generating capacity of dental plaque via arginine metabolism. An anti-caries effect may be expected from novel arginine-based oral care technologies due, in large part, to the ability of arginine to serve as an inducer of the ADS and a substrate for ammonia production by plaque bacteria. In addition, oral care products containing arginine may also enhance the ability of plaque bacteria to produce ammonia from naturally occurring substrates in saliva. Future studies should continue to dissect the underlying molecular basis for the individual and caries-related differences in arginolysis, ultimately allowing for the identification of individuals at greater risk for dental caries. Such experiments will expand the knowledge on the diversity of the oral alkaligenerating bacteria and their role in oral health and disease.

Acknowledgments The authors thank Drs. Floyd Dewhirst and Jorge Frias-Lopez from the Forsyth Institute for their valuable insights on the HOMD search of potential ADS-positive bacteria. Some of the work cited here has been supported by a grant from Colgate-Palmolive, which holds a patent for the novel arginine-based technology. Both authors have consulted for Colgate-Palmolive on an ad hoc basis.

\section{Compliance with Ethics Guidelines}

Conflict of Interest Dr. Marcelle M. Nascimento has received a grant and consulting fee or honorarium from Colgate-Palmolive.

Dr. Burne has 452 received a grant from NIH and honoraria for speaking at universities.

Human and Animal Rights and Informed Consent This article does not contain any studies with human or animal subjects performed by any of the authors.

\section{References}

Papers of particular interest, published recently, have been highlighted as:

- Of importance

•. Of major importance

1. Morou-Bermudez E, Elias-Boneta A, Billings RJ, Burne RA, Garcia-Rivas V, Brignoni-Nazario V, et al. Urease activity in dental plaque and saliva of children during a three-year study period and its relationship with other caries risk factors. Arch Oral Biol. 2011;56:1282-9.

2. Nascimento MM, Gordan VV, Garvan CW, Browngardt CM, Burne RA. Correlations of oral bacterial arginine and urea catabolism with caries experience. Oral Microbiol Immunol. 2009;24:89-95.

3.• Nascimento MM, Liu Y, Kalra R, Perry S, Adewumi A, Xu X, et al. Oral arginine metabolism may decrease the risk for dental caries in children. J Dent Res. 2013;92(7):604-8. This study provided the first analysis of the arginolytic potential of bacteria collected from site-specific supragingival plaque. The study revealed that plaque arginine metabolism varies greatly among children and tooth sites, which may affect their susceptibility to caries. 
4. Shu M, Morou-Bermudez E, Suarez-Perez E, Rivera-Miranda C, Browngardt CM, Chen YY, et al. The relationship between dental caries status and dental plaque urease activity. Oral Microbiol Immunol. 2007;22(1):61-6.

5. Burne RA, Parsons DT, Marquis RE. Environmental variables affecting arginine deiminase expression in oral streptococci; in Genetics and molecular biology of streptococci, lactococci, and enterococci. Washington: American Society for Microbiology; 1991.

6. Edgar WM, Higham SM. Plaque fluid as a bacterial milieu. J Dent Res. 1990;69:1332-6.

7. Burne RA, Marquis RE. Alkali production by oral bacteria and protection against dental caries. FEMS Microbiol Lett. 2000;193:1-6.

8. Liu YL, Nascimento M, Burne RA. Progress toward understanding the contribution of alkali generation in dental biofilms to inhibition of dental caries. Int J Oral Sci. 2012;4:135-40. This review covered many aspects of the oral bacterial systems for alkali production.

9. Wijeyeweera RL, Kleinberg I. Acid-base $\mathrm{pH}$ curves in vitro with mixtures of pure cultures of human oral microorganisms. Arch Oral Biol. 1989;34:55-64.

10. Kleinberg I. Effect of urea concentration on human plaque $\mathrm{pH}$ levels in situ. Arch Oral Biol. 1967;12:1475-84

11. Kleinberg I, Chatterjee R, Craw D, D'Angelo NK, Sandham HG. Metabolism of nitrogen by the oral mixed bacteria. Information Retrieval, Washington, DC, and London; 1979.

12. Acevedo AM, Montero M, Rojas-Sanchez F, Machado C, Rivera LE, Wolff M, et al. Clinical evaluation of the ability of CaviStat in a mint confection to inhibit the development of dental caries in children. J Clin Dent. 2008;19:1-8.

13. Acevedo AM, Machado C, Rivera LE, Wolff M, Kleinberg I. The inhibitory effect of an arginine bicarbonate/calcium carbonate CaviStat-containing dentifrice on the development of dental caries in Venezuelan school children. J Clin Dent. 2005;16:63-70.

14. Kraivaphan P, Amornchat C, Triratana T, Mateo LR, Ellwood R, Cummins D, et al. Two-Year caries clinical study of the efficacy of novel dentifrices containing $1.5 \%$ arginine, an insoluble calcium compound and 1,450 ppm fluoride. Caries Res. 2013;47:582-90.

15. Srisilapanan P, Korwanich N, Yin W, Chuensuwonkul C, Mateo LR, Zhang YP, et al. Comparison of the efficacy of a dentifrice containing $1.5 \%$ arginine and $1450 \mathrm{ppm}$ fluoride to a dentifrice containing $1450 \mathrm{ppm}$ fluoride alone in the management of early coronal caries as assessed using Quantitative Light-induced Fluorescence. J Dent. 2013;41(2):29-34.

16. Yin W, Hu DY, Fan X, Feng Y, Zhang YP, Cummins D, et al. A clinical investigation using quantitative light-induced fluorescence (QLF) of the anticaries efficacy of a dentifrice containing 1.5\% arginine and $1450 \mathrm{ppm}$ fluoride as sodium monofluorophosphate. $\mathrm{J}$ Clin Dent. 2013;24(A):15-22.

17. Yin W, Hu DY, Li X, Fan X, Zhang YP, Pretty IA, et al. The anticaries efficacy of a dentifrice containing $1.5 \%$ arginine and $1450 \mathrm{ppm}$ fluoride as sodium monofluorophosphate assessed using Quantitative Light-induced Fluorescence (QLF). J Dent. 2013;41(2):22-8.

18. Van Wuyckhuyse BC, Perinpanayagam HE, Bevacqua D, Raubertas RF, Billings RJ, Bowen WH, et al. Association of free arginine and lysine concentrations in human parotid saliva with caries experience. J Dent Res. 1995;74:686-90.

19. Higham SM, Edgar WM. Human dental plaque $\mathrm{pH}$, and the organic acid and free amino acid profiles in plaque fluid, after sucrose rinsing. Arch Oral Biol. 1989;34:329-34.

20. Casiano-Colon A, Marquis RE. Role of the arginine deiminase system in protecting oral bacteria and an enzymatic basis for acid tolerance. Appl Environ Microbiol. 1988;54:1318-24.

21. Poolman B, Driessen AJ, Konings WN. Regulation of arginineornithine exchange and the arginine deiminase pathway in Streptococcus lactis. J Bacteriol. 1987;169:5597-604.
22. Marquis RE, Bender GR, Murray DR, Wong A. Arginine deiminase system and bacterial adaptation to acid environments. Appl Environ Microbiol. 1978;53:198-200.

23. Griswold A, Chen YY, Snyder JA, Burne RA. Characterization of the arginine deiminase operon of Streptococcus rattus FA-1. Appl Environ Microbiol. 2004;70:1321-7.

24. Dong Y, Chen YY, Burne RA. Control of expression of the arginine deiminase operon of Streptococcus gordonii by CcpA and Flp. J Bacteriol. 2004;186:2511-4.

25. Ferro KJ, Bender GR, Marquis RE. Coordinately repressible arginine deiminase system in Streptococcus sanguis. Curr Microbiol. 1983;9:145-50.

26. Liu Y, Burne RA. Multiple two-component systems modulate alkali generation in Streptococcus gordonii in response to environmental stresses. J Bacteriol. 2009;191:7353-62.

27. Liu Y, Dong Y, Chen YY, Burne RA. Environmental and growth phase regulation of the Streptococcus gordonii arginine deiminase genes. Appl Environ Microbiol. 2008;74:5023-30.

28. Jakubovics NS, Gill SR, Iobst SE, Vickerman MM, Kolenbrander PE. Regulation of gene expression in a mixed-genus community: stabilized arginine biosynthesis in Streptococcus gordonii by coaggregation with Actinomyces naeslundii. J Bacteriol. 2008;190: 3646-57.

29. Barboza-Silva E, Castro AC, Marquis RE. Fluoride, triclosan and organic weak acids as modulators of the arginine deiminase system in biofilms and suspension cells of oral streptococci. Oral Microbiol Immunol. 2009;24:265-71.

30. Rogers AH. Utilization of nitrogenous compounds by oral bacteria. Aust Dent J. 1990;35:468-71.

31. Aas JA, Griffen AL, Dardis SR, Lee AM, Olsen I, Dewhirst FE, et al. Bacteria of dental caries in primary and permanent teeth in children and young adults. J Clin Microbiol. 2008;46:1407-17.

32. Corby PM, Lyons-Weiler J, Bretz WA, Hart TC, Aas JA, Boumenna T, et al. Microbial risk indicators of early childhood caries. J Clin Microbiol. 2005;43:5753-9.

33. Mager DL, Ximenez-Fyvie LA, Haffajee AD, Socransky SS. Distribution of selected bacterial species on intraoral surfaces. J Clin Periodontol. 2003;30:644-54.

34. Russell RR. How has genomics altered our view of caries microbiology? Caries Res. 2008;42:319-27.

35. Crielaard W, Zaura E, Schuller AA, Huse SM, Montijn RC, Keijser BJ. Exploring the oral microbiota of children at various developmental stages of their dentition in the relation to their oral health. BMC Med Genomics. 2011;4:22.

36. Sissons CH, Hancock EM, Cutress TW. The source of variation in ureolysis in artificial plaques cultured from human salivary bacteria. Arch Oral Biol. 1988;33:721-6.

37. Sissons CH, Hancock EM, Perinpanayagam HE, Cutress TW. The bacteria responsible for ureolysis in artificial dental plaque. Arch Oral Biol. 1988;33:727-33.

38. Sissons CH, Wong L, Hancock EM, Cutress TW. The $\mathrm{pH}$ response to urea and the effect of liquid flow in 'artificial mouth' microcosm plaques. Arch Oral Biol. 1994;39:497-505.

39. Burne RA, Zeng L, Ahn SJ, Palmer SR, Liu Y, Lefebure T, et al. Progress dissecting the oral microbiome in caries and health. Adv Dent Res. 2012;24:77-80.

40. Stephan RM. Changes in hydrogen-ion concentration on tooth surfaces and in carious lesions. J Am Dent Assoc. 1940;27:718-23.

41. Margolis HC, Duckworth JH, Moreno EC. Composition and buffer capacity of pooled starved plaque fluid from caries-free and cariessusceptible individuals. J Dent Res. 1988;67:1476-82.

42. Wijeyeweera RL, Kleinberg I. Arginolytic and ureolytic activities of pure cultures of human oral bacteria and their effects on the $\mathrm{pH}$ response of salivary sediment and dental plaque in vitro. Arch Oral Biol. 1989;34:43-53. 
43. Marquis RE. Oxygen metabolism, oxidative stress and acid-base physiology of dental plaque biofilms. J Ind Microbiol. 1995;15: 198-207.

44. Kleinberg I. Biochemistry of the dental plaque. Adv Oral Biol. 1970;4:43-90.

45. Huang X, Exterkate RA, Ten Cate JM. Factors associated with alkali production from arginine in dental biofilms. J Dent Res. 2012;91:1130-4.

46. Singer DL, Chatterjee R, Denepitiya L, Kleinberg I. A comparison of the acid-base metabolisms of pooled human dental plaque and salivary sediment. Arch Oral Biol. 1983;28:29-35.

47. Margolis HC, Duckworth JH, Moreno EC. Composition of pooled resting plaque fluid from caries-free and caries-susceptible individuals. J Dent Res. 1988;67:1468-75.

48. Rosen $\mathrm{S}$, Weisenstein PR. The effect of sugar solutions on $\mathrm{pH}$ of dental plaques from caries-susceptible and caries-free individuals. J Dent Res. 1965;44:845-9.

49. Stephan RM. Intra-oral hydrogen-ion concentration associated with dental caries activity. J Dent Res. 1944;23:257-66.

50. Gross EL, Leys EJ, Gasparovich SR, Firestone ND, Schwartzbaum JA, Janies DA, et al. Bacterial $16 \mathrm{~S}$ sequence analysis of severe caries in young permanent teeth. J Clin Microbiol. 2010;48:4121-8.

51. Gross EL, Beall CJ, Kutsch SR, Firestone ND, Leys EJ, Griffen AL. Beyond Streptococcus mutans: dental caries onset linked to multiple species by $16 \mathrm{~S}$ rRNA community analysis. PLoS One. 2012;7(10):e47722.

52. Ling Z, Kong J, Jia P, Wei C, Wang Y, Pan Z, et al. Analysis of oral microbiota in children with dental caries by PCR-DGGE and barcoded pyrosequencing. Microb Ecol. 2010;60:677-90.

53. Liu Y, Nascimento MM, Schulte R, Kalra R, Burne RA. Characterization of the arginolytic microflora of human oral biofilms. J Dent Res. 2012;91:1262.

54. Burne RA, Parsons DT, Marquis RE. Cloning and expression in Escherichia coli of the genes of the arginine deiminase system of Streptococcus sanguis NCTC 10904. Infect Immun. 1989;57:3540-8.

55. Griswold AR, Jameson-Lee M, Burne RA. Regulation and physiologic significance of the agmatine deiminase system of Streptococcus mutans UA159. J Bacteriol. 2006;188:834-41.
56. Griswold AR, Nascimento MM, Burne RA. Distribution, regulation and role of the agmatine deiminase system in mutans streptococci. Oral Microbiol Immunol. 2009;24:79-82.

57. Griswold AR, Chen YY, Burne RA. Analysis of an agmatine deiminase gene cluster in Streptococcus mutans UA159. J Bacteriol. 2004;186:1902-4.

58. Kleinberg I. Regulation of the acid-base metabolism of the dentogingival plaque and its relation to dental caries and periodontal disease. Int Dent J. 1970;20:451-71.

59. Kleinberg I, Jenkins GN. The $\mathrm{pH}$ of dental plaques in the different areas of the mouth before and after meals and their relationship to the $\mathrm{pH}$ and rate of flow of resting saliva. Arch Oral Biol. 1964;72: 493-516.

60. Beighton D. The complex oral microflora of high-risk individuals and groups and its role in the caries process. Community Dent Oral Epidemiol. 2005;33:248-55.

61. Lingstrom P, van Ruyven FO, van Houte J, Kent R. The pH of dental plaque in its relation to early enamel caries and dental plaque flora in humans. J Dent Res. 2000;79:770-7.

62. van Houte J, Lopman J, Kent R. The predominant cultivable flora of sound and carious human root surfaces. J Dent Res. 1994;73: 1727-34.

63. van Ruyven FO, Lingstrom P, van Houte J, Kent R. Relationship among mutans streptococci, "low-pH" bacteria, and lodophilic polysaccharide-producing bacteria in dental plaque and early enamel caries in humans. J Dent Res. 2000;79:778-84.

64. Becker MR, Paster BJ, Leys EJ, Moeschberger ML, Kenyon SG, Galvin JL, et al. Molecular analysis of bacterial species associated with childhood caries. J Clin Microbiol. 2002;40: 1001-9.

65. Beighton D, Al-Haboubi M, Mantzourani M, Gilbert SC, Clark D, Zoitopoulos L, et al. Oral Bifidobacteria: caries-associated bacteria in older adults. J Dent Res. 2010;89:970-4.

66. Kleinberg I. A new saliva-based anti-caries composition. Dentistry Today. 1999;18:98-103.

67. Nascimento MM, Browngardt C, Xiaohui X, Klepac-Ceraj V, Paster BJ, Burne RA. The effect of arginine on oral biofilm communities. Mol Oral Microbiol. 2013. doi:10.1111/omi.12044. 